\title{
Border Crossing to Inject Drugs in Mexico Among Injection Drug Users in San Diego, California
}

\author{
Tyson Volkmann • Sanghyuk S. Shin • Richard S. Garfein • \\ Thomas L. Patterson - Robin A. Pollini - Karla D. Wagner • \\ Irina Artamanova $\cdot$ Steffanie A. Strathdee
}

Published online: 26 March 2011

(C) The Author(s) 2011. This article is published with open access at Springerlink.com

\begin{abstract}
We examined correlates of ever injecting drugs in Mexico among residents of San Diego, California. From 2007 to 2010, injecting drug users (IDUs) in San Diego underwent an interviewer-administered survey. Logistic regression identified correlates of injection drug use in Mexico. Of 302 IDUs, $38 \%$ were Hispanic, $72 \%$ male and median age was 37; 27\% ever injected in Mexico; $43 \%$ reported distributive syringe sharing there. Factors independently associated with ever injecting drugs in Mexico included being younger at first injection, injecting heroin, distributive syringe sharing at least half of the time, and transporting drugs over the last 6 months. One-quarter of IDUs reported ever injecting drugs in Mexico, among whom syringe sharing was common, suggesting possible mixing between IDUs in the Mexico-US border region. Prospective studies should monitor trends in cross-border drug use in light of recent Mexican drug policy reforms partially decriminalizing drug possession.
\end{abstract}

Keywords Methamphetamine - Injection drug use · Mexico $\cdot$ Border $\cdot$ HIV $\cdot$ Drug abuse

T. Volkmann · S. S. Shin

Division of Global Public Health, San Diego State University/

University of California, San Diego, San Diego, CA, USA

R. S. Garfein - R. A. Pollini - K. D. Wagner - I. Artamanova S. A. Strathdee $(\square)$

Division of Global Public Health, University of California,

San Diego, San Diego, CA, USA

e-mail: sstrathdee@ucsd.edu

T. L. Patterson

Department of Psychiatry, University of California, San Diego,

San Diego, CA, USA

\section{Introduction}

San Diego, California is the most populous US city on the US-Mexico border. Located on an international drug trafficking route spanning from South America to the United States, illicit drugs such as heroin, methamphetamine and cocaine are readily available in San Diego and Tijuana, Mexico, which lies adjacent to San Diego in Mexico's northwest corner [1]. The corridor including the two cities is an unbroken metropolitan area. More than 50 million land border crossings between the US and Mexico take place at the San Ysidro border crossing per year, making it the busiest land border crossing in the world [2].

In 2008, the proportion of the population who reported injecting drugs in the Mexican state of Baja California, where Tijuana is located, was $4.8 \%$, compared to $0.2 \%$ elsewhere across Mexico [3]. Injection drug use is especially common in the central business district of Tijuana, where it is estimated that there are approximately 10,000 injection drug users (IDUs) [4]. More than 200 'shooting galleries' (places where people inject drugs in groups and syringes are rented or sold) were reported to be in operation in Tijuana in 2004 [5]. Previous research on IDUs in Tijuana found that heroin was the most frequently injected drug, but methamphetamine use is also high among IDUs [6]. The prevalence of methamphetamine use is highest in Baja California among Mexico's 32 states [7], stemming from its widespread production and trafficking through Baja California over the last two decades [8]. A qualitative study conducted in Tijuana in 2004 identified abundant use, cross-border use, and trafficking of methamphetamine [8]. While comparable estimates of IDU numbers are lacking for the city of San Diego, there may be as many as $25,000-28,000$ in San Diego County [9]. 
IDU populations are noted for their high level of mobility related to searching for work, safety, and access to illicit drugs, which has been associated with an elevated risk of acquiring and transmitting blood-borne infections [10]. For example, shooting gallery use and sharing of injection equipment was elevated among IDUs who had recently migrated from Puerto Rico to New York City [11]. Another study found associations between various drug scene roles, such as selling drugs and needles, and risky injection behaviors among Puerto Rican IDUs with high levels of mobility who travelled between the US and Puerto Rico [12]. In Brazil, spread of malaria from an endemic region to a non-endemic region was linked to syringe sharing among mobile IDUs [13]. Mixing between IDUs has also been implicated in HIV transmission across the border from Northeastern India into Nepal [14].

In border regions, where differences in neighboring drug markets may serve as a motivator for cross-border mobility, the role of injection drug use in the transmission of infectious diseases is of special interest. In a review article, Rachlis et al. listed many examples of links between drug trafficking, drug market volatility, and the spread of HIV along drug trafficking routes in several regions of the world, including Central Asia, port towns along the Black Sea and northeastern states in India adjacent to Myanmar [10]. In the border region of China and Vietnam, Chinese HIV-positive IDUs were more likely to live closer to the border and cross the border to purchase drugs than HIV-negative IDUs $[15,16]$, which is believed to have contributed to the spread of HIV among IDUs in Vietnam [17].

High and/or rising prevalence of HIV, HCV, TB and syphilis among IDUs in the border region may pose risks to IDUs who travel to Tijuana from neighboring San Diego to obtain and/or inject drugs and for those traveling from Tijuana to San Diego. HIV prevalence among male and female IDUs in Tijuana was 4 and 12\%, respectively [18], compared to $5 \%$ among male and $1 \%$ among female IDUs in San Diego (personal communication, Dr. Richard Garfein Sept 2010). The prevalence of latent tuberculosis infection was 67\% among IDUs in Tijuana in 2007 [19], and cross-border mobility of IDUs in the US-Mexico border region was associated with heightened odds of lifetime TB risk [20]. Prevalence of syphilis infection among IDUs in Tijuana in 2006-2007 was 6\% among male and 16\% among female IDUs [21]. The high proportion of active syphilis infections among IDUs in Tijuana suggests that syringe sharing could promote parenteral syphilis transmission [22].

Spread of infections in the Mexico-US border region may be facilitated by highly mobile populations, including IDUs, who reside close to the border and can cross freely between these neighboring countries, but few studies have examined this phenomenon empirically. A study by members of our team in 2005 showed that among 222 IDUs in Tijuana, $12 \%$ crossed the border to the US in the 6 months prior to the interview; IDUs who had been deported to Mexico injected more frequently and were less likely to receive medical care, drug treatment, or HIV testing [23], which could imply a greater risk for blood borne transmission. In a larger study of 1056 IDUs who resided in Tijuana in 2006-2007, 78\% had ever crossed into the United States and 58\% had used drugs there [24].

In August 2010, federal Mexican drug policy was enacted that partially decriminalized possession of small quantities of specific drugs for personal consumption (e.g., methamphetamine, heroin, cocaine, marijuana, LSD) [25]. As these laws become adopted in Mexican states, this policy shift could affect drug using behaviors and mobility in the Mexico-US border region. To our knowledge, no studies have examined the frequency and factors associated with border crossing among IDUs in the US who travel to Mexico. The current study, which was conducted prior to changes in Mexico's drug possession laws, examined the prevalence and correlates of ever injecting drugs in Mexico among IDUs living in San Diego.

\section{Methods}

\section{Data Collection}

Between 11/2007 and 02/2010, we recruited IDUs in San Diego, California to study their experiences with retail illicit drug markets and cross-border mobility. Eligibility criteria included residing in San Diego County, having injected drugs within the last 6 months and being at least 18 years old. Participants were recruited through street outreach at the San Diego syringe exchange program, through word of mouth, and referrals from other observational studies.

The study instrument consisted of a questionnaire eliciting data on demographic characteristics, drug use behaviors such as injection frequency, receptive syringe sharing (i.e., having used a needle someone else had already used), distributive syringe sharing (i.e. having passed on, rented or sold a used needle they had used to someone else), and participation in the drug market over the last 6 months (e.g. selling, packaging or transporting drugs). Participants were specifically asked if they traveled to Mexico in their lifetime and in the last 6 months, if they injected drugs in Mexico and if they engaged in receptive and distributive syringe sharing in Mexico, but were not specifically asked if they transported drugs over the border. Additionally, information was obtained on perceived changes in drug market conditions, such as whether the 
price, purity, and availability of heroin, methamphetamine, cocaine and other drugs had increased, decreased or stayed the same over the last 6 months. Variables reflecting perceptions and participation in the drug market were based in part on questions derived from a survey conducted by the San Diego Association of Governments among San Diego arrestees. Questions were interviewer-administered via computer-assisted programmed interview (CAPI) using Questionnaire Development System (QDS) software (Nova, Bethesda, Maryland, USA). Subjects were compensated USD \$20 for participation. The UCSD Human Research Protection Program approved the study protocol.

\section{Laboratory Testing}

HIV antibody testing was conducted using the OraQuick ADVANCE Rapid HIV-1/2 Antibody Test (OraSure Technologies, Inc., Bethlehem, PA). Pre and post test HIV counseling was conducted for all participants. Those who were previously unaware of their HIV status and tested HIV-positive were referred to county clinics for confirmatory testing, counseling and medical care. Participants were asked whether they had ever tested positive for syphilis, gonorrhea, and Chlamydia, chancroid, and other sexually transmitted infections (STIs) but were not tested for these infections.

\section{Statistical Analysis}

Participants who had ever injected drugs in Mexico were compared to those who had not, first using descriptive statistics (chi-square tests for categorical variables, Fisher's exact test for dichotomous variables, and Wilcoxon ranksum tests for continuous variables). Logistic regression was used to identify correlates of ever having injected drugs in Mexico, selecting variables that were significant at the 5\% level in univariate models for potential inclusion in multivariate models. The likelihood ratio test was used to compare nested multivariate models. Variables that were significant at $P \leq 0.05$ were retained for the final model. In order to substantiate our results we repeated our logistic regression analysis on a subset of subjects, comparing those who injected in Mexico during the last 6 months to those who had not.

\section{Results}

Of the 304 participants initially enrolled, two were excluded because they had missing information on whether or not they had ever injected drugs in Mexico. Of the 302 IDUs included in the analysis, most were male $(71.5 \%)$ and born in the United States $(91.7 \%)$. Although
$68.1 \%$ were White, $38(12.6 \%)$ described themselves as Latino/Hispanic and 77 (25.5\%) as "other"; 7 (2.3\%) were born in Mexico while 14 (4.6\%) were born in another country. Median age was 37 and median age at first injection of drugs was 21 years (range: 9-53), respectively. Overall, $242(80.1 \%)$ ever crossed the border into Mexico and 97 (32.2\%) crossed into Mexico in the last 6 months. A total of $83(27.5 \%)$ reported ever injecting drugs in Mexico, of whom $36(43.4 \%)$ reported having done so in the last 6 months. Of the 83 subjects who ever injected in Mexico, 73.5\% had injected with someone else, $41.0 \%$ engaged in distributive syringe sharing and $21.7 \%$ engaged in receptive syringe sharing while they were in Mexico.

As shown in Table 1, compared to other IDUs, those who had ever injected in Mexico were younger at first injection (median age 19 vs. 21 years; $P=0.002$ ), and were more likely to report the following behaviors during the last 6 months: injecting heroin, injecting drugs more than once per week, renting or lending a syringe at least half the time, and injecting with someone in the US. Those who had ever injected in Mexico were also more likely to report being involved in the drug market, for example, by packaging drugs or transporting drugs in the last 6 months. Finally, IDUs who had ever injected in Mexico were more likely to report the perception that the price of at least one drug went down or stayed the same in the last 6 months, with the majority of those responding noticing that the price of methamphetamine went down or stayed the same $(P<0.05)$. It should be noted that these risk behaviors could have occurred in Mexico or the US or both. Variables that did not differ between those who injected in Mexico and those who did not included HIV serostatus, self reported STI status, and sexual behaviors.

Factors that were independently associated with ever injecting drugs in Mexico in multivariable analysis included being younger at first injection $(\mathrm{AOR}=0.95$ per year; $95 \% \mathrm{CI}=0.91-0.99)$, injecting heroin ( $\mathrm{AOR}=2.11 ; 95 \%$ $\mathrm{CI}=1.15-3.88$ ), renting or lending a used syringe to another person at least half of the time (AOR $=2.35 ; 95 \%$ $\mathrm{CI}=1.11-4.95)$, and transporting drugs over the last 6 months $(\mathrm{AOR}=2.24 ; 95 \% \mathrm{CI}=1.22-4.11)$ (Table 2). Perceiving that the price of at least one drug went down or stayed the same over the last 6 months was also independently associated with ever injecting drugs in Mexico $(\mathrm{AOR}=2.60 ; \quad 95 \% \quad \mathrm{CI}=1.30-5.18) . \quad$ A multivariate model that replaced the variable 'transporting drugs' with 'packaging drugs' yielded similar associations (results not shown). The sub-analysis that compared IDUs who injected in Mexico during the last 6 months versus those who had not generated similar parameter estimates (results not shown). 
Table 1 Demographic, injection, and drug perception risks associated with cross-border injection drug use by San Diego drug users traveling to Tijuana, Mexico $(\mathrm{N}=302)$

\begin{tabular}{|c|c|c|c|c|}
\hline & \multicolumn{2}{|c|}{ Unadjusted proportions } & \multirow[b]{2}{*}{ Univariate OR (95\% CI) } & \multirow[b]{2}{*}{$P$ value } \\
\hline & $\begin{array}{l}\text { Injected in Mexico } \\
(\mathrm{N}=83)\end{array}$ & $\begin{array}{l}\text { Did not inject in Mexico } \\
(\mathrm{N}=219)\end{array}$ & & \\
\hline \multicolumn{5}{|l|}{ Demographics } \\
\hline Female versus male & $22(26.5 \%)$ & $57(26.0 \%)$ & $1.00(0.56-1.78)$ & 0.99 \\
\hline White versus Hispanic/other & $60(72.3 \%)$ & $127(58.0 \%)$ & $1.52(0.68-3.42)$ & 0.31 \\
\hline Born in the United States & $76(91.6 \%)$ & $205(93.6 \%)$ & $0.49(0.11-2.26)$ & 0.66 \\
\hline At least high school education & $59(71.1 \%)$ & $142(64.8 \%)$ & $1.33(0.77-2.31)$ & 0.31 \\
\hline \multicolumn{5}{|l|}{ Injection Risks/Behaviors } \\
\hline Median age first injected drugs (IQR) & $19(15,23)$ & $21(18,29)$ & $0.93(0.89-0.97)$ & $<0.01$ \\
\hline Injected heroin* & $55(66.3 \%)$ & $92(42.0 \%)$ & $2.71(1.60-4.60)$ & $<0.01$ \\
\hline Injected heroin $>$ once per week $*$ & $40(48.2 \%)$ & $62(28.3 \%)$ & $2.36(1.40-3.97)$ & $<0.01$ \\
\hline Injected methamphetamine* & $57(69.5 \%)$ & $145(66.2 \%)$ & $1.16(0.67-2.01)$ & 0.59 \\
\hline Injected drugs $>$ once per week* & $63(75.9 \%)$ & $130(62.8 \%)$ & $1.87(1.05-3.32)$ & 0.03 \\
\hline Rented or lent syringe at least half the time* & $20(24.1 \%)$ & $25(11.7 \%)$ & $2.39(1.24-4.59)$ & $<0.01$ \\
\hline Injected with someone in US* & $33(39.8 \%)$ & $19(8.8 \%)$ & $6.81(3.57-12.97)$ & $<0.01$ \\
\hline Crossed the US-Mexico border* & $40(48.8 \%)$ & $57(26.0 \%)$ & $2.71(1.60-4.59)$ & $<0.01$ \\
\hline \multicolumn{5}{|l|}{ Drug Market Roles } \\
\hline Packaged drugs* & $25(32.1 \%)$ & $34(16.6 \%)$ & $2.37(1.30-4.33)$ & $<0.01$ \\
\hline Transported drugs* & $32(41.0 \%)$ & $53(25.9 \%)$ & $2.00(1.15-3.45)$ & 0.01 \\
\hline \multicolumn{5}{|l|}{ Drug Perceptions } \\
\hline $\begin{array}{l}\text { Price of at least one drug went down } \\
\text { or stayed the same* }\end{array}$ & $62(76.5 \%)$ & $124(60.2 \%)$ & $2.17(1.20-3.85)$ & $<0.01$ \\
\hline Purity of at least one drug went up* & $12(15.0 \%)$ & $19.0(9.6 \%)$ & $1.49(0.87-2.56)$ & 0.15 \\
\hline Price of meth went down or stayed the same* & $66(81.5 \%)$ & $137(66.5 \%)$ & $2.22(1.18-4.17)$ & 0.01 \\
\hline
\end{tabular}

Bold values indicate significant at the $P<0.05$ level

* Past 6 months

Table 2 Factors independently associated with cross-border injection drug use by San Diego drug users traveling to Tijuana, Mexico $(\mathrm{n}=302)$

\begin{tabular}{ll}
\hline & AOR (95\% CI) \\
\hline Age at first drug injection (per year increase) & $0.95(0.91-0.99)$ \\
Injected heroin* & $2.11(1.15-3.88)$ \\
Rented or lent syringe at least half of the time* & $2.35(1.11-4.95)$ \\
Involved in transporting drugs* & $2.24(1.22-4.11)$ \\
Perceived that the price of at least one drug & $2.60(1.30-5.18)$ \\
decreased or stayed the same* & \\
\hline
\end{tabular}

* Past 6 months

\section{Discussion}

In this sample of IDUs recruited in San Diego, CA from 2009 to 2010, approximately one-quarter reported ever injecting drugs in Mexico, of whom nearly half reported injecting drugs in Mexico over the last 6 months. More than one-fifth reported receptive syringe sharing in Mexico and two-fifths reported distributive syringe sharing in Mexico, suggesting there is considerable cross-border mobility and possible mixing among IDUs in San Diego who travel to Tijuana. IDUs who ever injected drugs in Mexico were more likely to be younger heroin injectors who were involved in some riskier drug behaviors, such as syringe sharing, than those who never injected in Mexico. They were also more likely to be involved in the drug market and to report perceived changes in San Diego's retail drug prices.

In the current study, IDUs who had ever injected in Mexico were significantly more likely to have engaged in distributive syringe sharing and transporting drugs. The finding that IDUs who ever injected drugs in Mexico were more likely to have transported or packaged drugs implies a connection to the illicit drug trade. Various roles in the drug scene, such as selling drugs, have been associated with elevated odds of injection drug use and syringe sharing $[12,26]$. Another study from Asia found similar results along a major drug supply route: IDUs who traveled from China, where drugs were scarce, to a region in 
Vietnam where drugs were plentiful, were more likely to cross the border to purchase drugs than non-IDUs [27].

IDUs who had ever injected drugs in Mexico were two and a half times more likely to have perceived a decrease in the price of at least one drug in San Diego compared to IDUs who had never injected in Mexico. This association appeared to be driven by a perceived decrease in the retail price of methamphetamine. Since the mid-1990s, Mexican methamphetamine traffickers have been operating "super labs" which are capable of producing more than 10 pounds of methamphetamine in $24 \mathrm{~h}$ [28]. These super labs have been implicated in the increased supply of methamphetamine from Mexico to the United States, and may have affected its retail price. Regulation of precursor chemicals by the United States and Canada in the early 2000s limited supply of methamphetamine produced by super labs [29] and may have led to increased prices. A 2008 report from San Diego found that $76 \%$ of local methamphetamine arrestees perceived an increase in the price of methamphetamine between 2006 and 2008 [30], but a more recent report from 2009 found mixed results for market price trends depending on the quantity, with decreasing prices per-pound, indicating a possible shift in the market [31]. The finding that San Diego IDUs who injected in Mexico had perceived a price decrease in drugs is unexpected, given the San Diego methamphetamine market conditions at the time of the study. Our findings could imply that IDUs who injected in Mexico and who were price-sensitive could be crossing into Mexico to purchase methamphetamine, where it is less expensive, with the intention of reselling it in San Diego. This is speculative, however, and further investigation is needed to explain this finding. IDUs who are involved in the drug trade may be more sensitive to changes in the drug market and could ostensibly be more affected by recent changes to Mexico's drug possession laws if methamphetamine becomes easier to acquire in Mexico. However, since our analysis was cross-sectional and the relationships between mobility and drug market factors such as purity, price and availability are complex, caution should be exercised in the interpretation of our data. For example, price and purity of methamphetamine in the United States are also subject to influences such as policy changes in the US and Mexican regulating precursor chemicals [32].

In support of the literature indicating that IDUs who are mobile tend to be more likely to report riskier injection behavior sharing [10], IDUs who injected drugs in Mexico were more likely to have engaged in distributive syringe sharing, and were younger when they initiated injection drug use. A recent study of IDUs living in Tijuana showed that $78 \%$ had ever crossed the border into the United States, but only $7 \%$ had done so in the last year [24]. In contrast, our study found that $80 \%$ of IDUs living in San Diego had ever crossed the Mexican border, of whom $32 \%$ had done so in the last 6 months. Almost half of Tijuana IDUs had injected with someone from the United States, though it is unknown whether those injection events occurred in the US or in Mexico [24]. These data suggest that there is considerable mobility among IDUs living in the US/Mexico border region, and raises important questions about the extent of interaction among US- and Mexico-based IDUs. Future studies will be needed to explore the extent to which IDUs engage in drug and sexual risk behaviors with members of social networks on either side of the border, which could have important implications for the transmission of bloodborne pathogens.

Our analysis was limited by the fact that our outcome variable captured lifetime injection experiences in Mexico relative to several of the independent variables whose time frame was during the 6 months before the interview. However, nearly half of our participants who ever injected in Mexico crossed into Mexico during the last 6 months, of whom about one-quarter of those injected in Mexico. Additionally, our sub-analysis that compared those who injected in Mexico during the last 6 months versus those who had not yielded similar associations, suggesting that this issue may not have seriously biased our findings. Other limitations include the potential for selection bias due to convenience sampling, as well as socially desirable responding which may have attenuated some associations.

Prospective studies are needed to monitor trends in cross-border drug use, its relationship to the drug market, and its impact on behaviors and health outcomes for residents of both the US and Mexico. Mexico's drug policy reforms which partially decriminalize small amounts of illicit drugs could potentially influence infectious disease transmission by enticing IDUs from the US to cross the Mexican border more frequently as 'drug tourists'. Such trends should be monitored closely.

Acknowledgments We acknowledge support from the National Institute on Drug Abuse (grants R21 DA024381 and K01 DA031031 and T32 DA023356). We thank Cindy Burke from the San Diego Association of Governments for sharing questions on drug market participation, Carlos Vera, Tim Ross, and Jim Zians for assistance with data collection, the study participants, and Katy Kessler for assistance with manuscript preparation.

Open Access This article is distributed under the terms of the Creative Commons Attribution Noncommercial License which permits any noncommercial use, distribution, and reproduction in any medium, provided the original author(s) and source are credited.

\section{References}

1. Bucardo $\mathrm{J}$, et al. Historical trends in the production and consumption of illicit drugs in Mexico: implications for the 
prevention of blood borne infections. Drug Alcohol Depend. 2005;79:281-93.

2. SANDAG. San Ysidro-Vehicle Crossings San Ysidro-Vehicle Crossings. 2010. http://www.sandag.org/uploads/publicationid/ publicationid_1424_9306.pdf.Last accessed on 26 Aug 2010.

3. Moreno JGB, et al. Tackling HIV and drug addiction in Mexico. Lancet. 2010;376:493-5.

4. Brouwer $\mathrm{KC}$, et al. Estimated numbers of men and women infected with HIV/AIDS in Tijuana, Mexico. J Urban Health. 2006;83:299-307.

5. Philbin M, et al. Shooting gallery attendance among IDUs in Tijuana and Ciudad Juarez, Mexico: correlates, prevention opportunities, and the role of the environment. AIDS Behav. 2008;12:552-60.

6. Strathdee SA, et al. Vivo para consumirla y la consumo para vivir ["I live to inject and inject to live"]: high-risk injection behaviors in Tijuana, Mexico. J Urban Health. 2005;82:58-73.

7. National Council against Addictions NIoPRdIF, National Institute on Public Health: 2008 national household survey on addictions, Mexico. (in Spanish);2008.

8. Case $\mathrm{P}$, et al. At the borders, on the edge: use of injected methamphetamine in Tijuana and Ciudad Juarez, Mexico. J Immigr Minor Health. 2008;10:23-33.

9. Services CoSD-C.Clean Syringe Exchange Pilot Program Clean Syringe Exchange Pilot Program 2007. http://www.sandiego.gov/ communityservices/cleansyringe/\#facts. Last accessed on 15 Sep 2010.

10. Rachlis B, et al. Migration and transmission of blood-borne infections among injection drug users: understanding the epidemiologic bridge. Drug Alcohol Depend. 2007;90:107-19.

11. Deren S, et al. Migration and HIV risk behaviors: Puerto Rican drug injectors in New York City and Puerto Rico. Am J Public Health. 2003;93:812-6.

12. Friedman SR, et al. Drug-scene roles and HIV risk among Puerto Rican injection drug users in East Harlem, New York and Bayamon, Puerto Rico. J Psychoactive Drugs. 2002;34:363-9.

13. Bastos F, et al. Co-infection with malaria and HIV in injecting drug users in Brazil: a new challenge to public health? Addiction. 1999;94:1165-74.

14. Nepal B. Population mobility and spread of HIV across the IndoNepal border. J Health Popul Nutr. 2007;25:267-77.

15. Hammett TM, et al. Correlates of HIV status among injection drug users in a border region of southern China and northern Vietnam. J Acquir Immune Defic Syndr. 2005;38:228-35.

16. Des Jarlais DC, et al. Patterns of HIV prevalence among injecting drug users in the cross-border area of Lang Son Province, Vietnam, Ning Ming County, Guangxi Province, China. BMC Public Health. 2005;5:89.
17. Kato K, et al. Closely related HIV-1 CRF01 AE variant among injecting drug users in Northern Vietnam: evidence of spread across the Vietnam-China border. AIDS Res Hum Retroviruses. 2001;17:113-23.

18. Strathdee S, et al. Differential effects of migration, deportation on HIV infection among male, female injection drug users in Tijuana, Mexico. PLoS One. 2008;3:e2690.

19. Garfein R, et al. High prevalence of latent tuberculosis infection among injection drug users in Tijuana, Mexico. Int J Tuberc Lung Dis. 2009; 13:626-32.

20. Deiss R, et al. Influences of cross-border mobility on tuberculosis diagnoses and treatment interruption among injection drug users in Tijuana, Mexico. Am J Public Health. 2009;99:1491-5.

21. Strathdee SA, et al. Differential effects of migration, deportation on HIV infection among male, female injection drug users in Tijuana, Mexico. PLoS One. 2008;3:e2690.

22. Loza $\mathrm{O}$, et al. Drug-related behaviors independently associated with syphilis infection among female sex workers in two MexicoUS border cities. Addiction. 2010;105:1448-56.

23. Brouwer KC, et al. Deportation along the U.S.-Mexico border: its relation to drug use patterns and accessing care. J Immigr Minor Health. 2009;11:1-6.

24. Wagner $\mathrm{K}$, et al. Cross-border drug injection relationships among injection drug users in Tijuana, Mexico. Drug Alcohol Depend. 2001;113:236-41.

25. Moreno $\mathrm{J}$, et al. Tackling HIV and drug addiction in Mexico. Lancet. 2010;376:493-5.

26. Latkin C, et al. Social context of needle selling in Baltimore, Maryland. Subst Use Misuse. 2006;41:901-13.

27. Beyrer $\mathrm{C}$, et al. Overland heroin trafficking routes and HIV-1 spread in south and south-east Asia. AIDS. 2000;14:75-83.

28. USDEA.Drug Trafficking in the United States Drug Trafficking in the United States http://www.justice.gov/dea/pubs/state_fact sheets.html. Last accessed on 31 Aug 2010.

29. Brouwer KC, et al. Trends in production, trafficking, and consumption of methamphetamine and cocaine in Mexico. Subst Use Misuse. 2006;41:707-27.

30. SANDAG: 2008 Methamphetamine addendum-Aggregate data 2008.

31. Pollini R (2010). Drug use and abuse in San Diego county, California. Oral presentation to the national institute on drug abuse's community epidemiology work group. San Diego;2010.

32. Cunningham J, et al. Impact of US and Canadian precursor regulation on methamphetamine purity in the United States. Addiction. 2009;104:441-53. 